zur Zeit ber Wolzhandel fich erfrent, vielen eine millfommene Erifietnung fein und in ben beteiligten Rreijen jreundidje $2 \mathfrak{u}$ fnatgme finden.

\title{
IV. Alutizen.
}

\author{
forftleḩrlingsfł̆ule $\mathfrak{z}$ Templin.
}

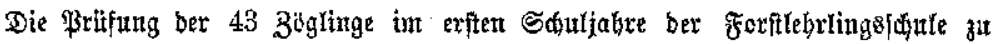

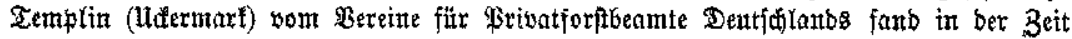

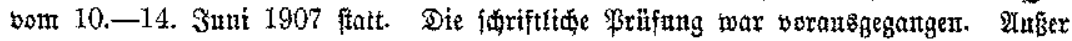

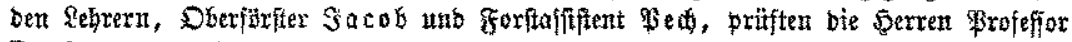
Dr. S

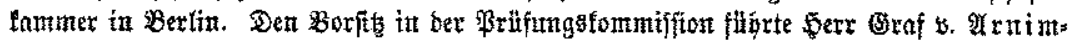
SBoitzentaxxg.

Das Enbergebnis war redit erfretfith, bentn affe \$rifffinge beftanben, unb stoar 3 mit Rote I (jegr gat), 16 mit Rote II (gut) mo 23 ntit Rote III (gentigenb). Eit

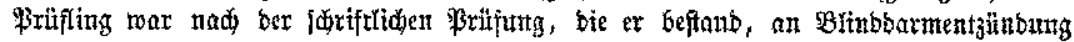

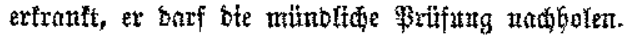

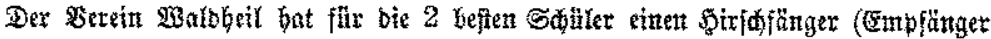

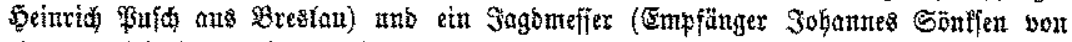
Bargnnt bei \$̧tifum (Golftein) gefpiftet.

Das 2. Eduttight begann att 1. Suli 1907. Bon 63 MnmeYbungen twurbent

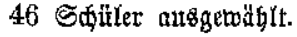

\section{Ulnfallverfitherung von Studierenden.}

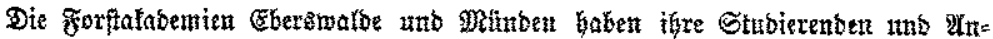

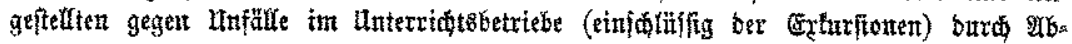

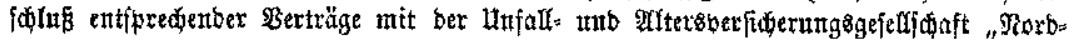

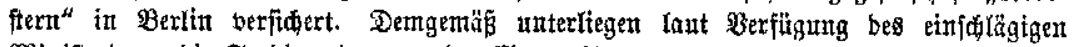

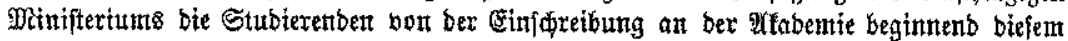

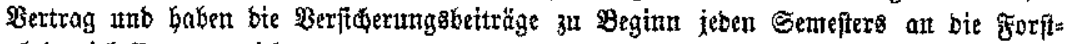
alabemiefaffe zut ettriditen.

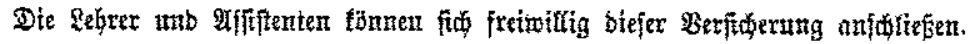

\section{Untfitedelung dex Ģählenbrüter.}

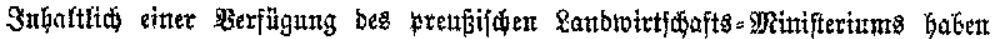

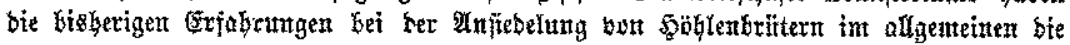

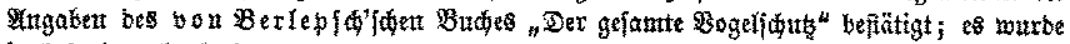
ingefortbere beobadtet:

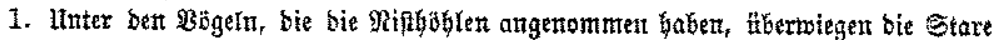

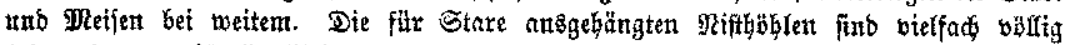

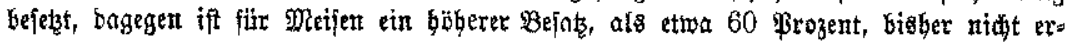
zielt worben. 